\title{
Habitação saudável e ambientes favoráveis à saúde como estratégia de promoção da saúde
}

\author{
Healthy housing and healthy environments \\ as a strategy for health promotion
}

Abstract In this article, Healthy H ousing is discussed as a potential field of knowledge and practices to be applied in the Health Promotion strategy and as an instrument in a larger discussion of problems in health and living standards. The development and consolidation of $\mathrm{H}$ ealth Promotion is presented focusing the discussion on two fields of action: healthy public policies and the establishment of healthy environments. The concepts of habitability and ambience are presented as a path conducive to reflection and the development of closer ties between $\mathrm{Health}$ Promotion and Healthy Housing.

Keys words $\mathrm{H}$ ealthy housing, $\mathrm{H}$ ealth promotion, Habitability, Environment comfort
Resumo Nesteartigo, discute-sea H abitação Saudável enquanto campo potencial de conhecimento e de práticas a serem aplicadas na estratégia de Promoção da Saúde, como instrumento de abordagem ampliada de di scussão dos problemas relativos à saúde eà qualidade de vida. A presenta-se o desenvolvimento e a consolidação da Promoção da Saúde, centrando a discussão em dois campos de ação: políticas públicas saudáveis e criação de ambientes favoráveis à saúde. Como caminho de reflexão e aproximação dos campos da Promoção da Saúdee da Habitação Saudável, são utilizados os conceitos de habitabilidade e de ambiência. Palavras-chave Habitação saudável, Promoção da saúde, Habitabilidade, Ambiência 
Introdução

Do ponto de vista do paradigma do ambiente como determinante da saúde, a habitação se constitui em um espaço de construção e consolidação do desenvolvimento da saúde. A família tem na habitação seu principal espaço de sociabilidade, transformando-a em um espaço essencial veículo da construção e desenvolvimento da Saúdeda Família. A habitação éentendida, desta forma, como a ação do habitat em um espaço que envolve o elemento físico da moradia (e/ou qualquer ambiente físico construído), a qualidade ambiental nesteespaço construído, no seu entorno e nas suas inter-relações. Conseqüentemente, há uma necessidade de um enfoque sociológico etécnico para o enfrentamento dosfatores derisco, desde o início do processo de idealização e construção deste espaço, por meio da promoção adequada do desenho, da localização, da habilitação, da adaptação, gerenciamento, uso e manutenção da habitação e de seu entorno ${ }^{1}$.

Assim, um programa que incentive a construção de habitat saudável, aliando a iniciativa da habitação saudável e da estratégia da atenção primária ambiental, vem a se constituir em uma ferramenta para otimização dos resultados em um processo gradativo de melhoria da qualidade de vida ${ }^{1}$. Tal processo só éefetivado por intermé dio da elaboração de políticas públicas saudáveis, que exigem ação intersetorial, interdisciplinar e uma nova institucionalidade social, materializada através de propostas que visem à territorialização, à vinculação, à responsabilização eà resolutividade com um olhar integral sobre 0 ambiente em todas as suas dimensões, onde estão inseridos os indivíduos e suas famílias. 0 desafio desta proposta estaria na construção de formas de intervenção sobre os fatores determinantes da saúde no espaço construído e no seu entorno (biologia humana, meio ambiente e estilo de vida), integrando a Promoção da Saúde à H abitação Saudável. N este sentido, a habitação com suas diversas extensões, onde 0 indivíduo também habita ${ }^{1}$ deve ser pensada como determinante da saúde e consolidação do desenvolvimento social. Para isto, é necessário o aprofundamento destes dois campos, o que será visto no item a seguir.

Portanto, este artigo partirá de uma análise da inserção da Habitação Saudável dentro do movimento da Promoção da Saúde, para em seguida mostrar a importância dos conceitos de habitabilidadee ambiência dentro desta inserção.
O movimento da promoção da saú de e da habitação saudável

A Promoção de Saúde vem se consolidando exatamente enquanto espaço de reflexão da história social do processo saúde-doença, como campo de implementação de estratégias que aliem o conhecimento e as práticas, incorporando e analisando os determinantes biopsicossociais, econômicos, culturais, políticos e ambientais. Utiliza como principal estratégia a ampliação do conceito de saúde e de qualidade de vida, propondo a articulação com outros setores, como habitação, urbanismo, meio ambiente, educação, cultura, trabalho, economia, justiça, transporteelazer, entre outros. Além do trabalho intersetorial, énecessário também a observância dos determinantes sociais, de modo a favorecer uma maior mobilização social na implementação de ações que promovam a sustentabilidade, a defesa pública da saúde (advocacy), a eqüidade e a justiça social ${ }^{2}$.

A Promoção da Saúde no Brasil apresenta como proposta a reorientação dos sistemas de serviços de saúde e de gestão ambiental. Propõe o redesenho de programas de saúde que contemplem a integralidade, a humanização e a eqüidade. Enfatiza ainda a intersetorialidade como política de promoção da qualidade de vida ea participação / empoderamento, com o intuito de val orização da capacidade crítica e reflexiva dos agentes sociais diante do contexto e dos determinantes econômicos, sociais, culturais e ambientais em saúde 3 .

Como campo de operacionalização de políticas públicas e de criação de condições favoráveis ao desenvolvimento da saúde, a Promoção da Saúde inclui processos de educação continuada, reforçando habilidades pessoais e empoderando a comunidade para a reflexão conjunta de problemas e a busca de soluções, através da mediação entre os diversos setores envolvidos.

Como movimento em constante evolução, a Promoção da Saúde vai ampliando o conceito de saúde e se relacionando com outros conceitos como o do ambiente, como ocorrido em 1991, em Sundsvall. N esta relação entre a saúde e ambiente, foram consideradas as dimensões físicas (água, esgoto, resíduos sólidos domésticos e industriais, drenagem urbana, controle de vetores, proteções da atmosfera, solo, rios, lagoas e oceanos) e os fatores sociais, políticos; econômicos e culturais, enfatizando a necessidade da criação de ambientes saudáveis. 
A iniciativa da Habitação Saudável éanterior ao movimento de Promoção da Saúde, pois se desenvolveu a partir de 1982, em Buffalo/Nova York, no Centro de M edicina Coletiva ${ }^{4}$. Esta iniciativa teve como resultado a criação deum Centro de Saúde na Habitação, promulgando o conceito de higiene do meio, capacitando voluntários para apoiar a comunidade nas questões relativas à precariedade do meio. A Universidade de Nova York/Buffalo desenvolvia projetos em H onduras na Comunidade Flor Del Campo, na Bolívia, em cooperação com a Universidad San Simón de Cochabamba, e na Venezuela, com a Escola de Saúde Pública Arnoldo Gavaldón, em Maracay.

Considera-se, então, que o Centro de Saúde na H abitação de Nova York é um antecedente; porém, há outros antecedentes com outros grupos detrabalho da Região. Em Havana, por exemplo, no Instituto Nacional de Higienee Epidemiologia, em Cuba, teve início a investigação sistemática da habitação, principalmente projetos típicos, abarcando a qualidade do ar interior, acústica, iluminação, microclima e ventilação, vibrações, introduzindo estudos epidemiológicos de impacto, tudo conduzido para a melhoria do desenho da habitação no nível de projetos construtivos e dentro de uma ótica intersetorial.

$\mathrm{Na}$ própria Venezuela, a Universidade dos Andes, em M érida, nos anos 90, conduziu um Plano de Habitação Rural com desenhos de espaços saudáveis que estavam dentro da ótica do saneamento, queincluía luta contra vetores, água e disposição de resíduos, como também conforto climático e funcionalidade.

Também no mesmo período, a Faculdade de Arquitetura da Universidade Autônoma do M éxico - UNAM, na Cidade do M éxico, come çou a vincular os termos da habitação e da saúde dentro da ótica de formação de arquitetos. Tratava-se do desenvolvimento de uma linha de teses de arquitetura baseada nesta temática, que se estendeu a universidades de outros estados mexicanos.

Ao mesmo tempo, em Santiago de Chile, a Pontifícia Universidade Católica começou a desenvolver intervenções sociais com as amas de casas sociais, particularmentena área de aten ção psicológica para famílias com disfunções, como foi o caso da Vila dos Navios, em Santiago. E, na Nicarágua, se iniciou um trabalho em Higiene da Habitação com moradores de assentamentos marginais por parte da UNAM . Na J amaica, também havia um grupo que desenvolvia atividades no campo da melhoria das habitações de inte- resse social. Na Argentina, em Chaco, desde fins dos anos 80 , se trabal hava com melhoramentos das habitações, auspiciado pelo Clube de Leões, com o acompanhamento da Organização Panamericana da Saúde - OPS4.

Dessa forma, o processo iniciado com o Centro deSaúdena H abitação, em Buffal o/N ova York, gerou um movimento de pesquisa e produção de conhecimento técnico e aplicado em torno do ambiente construído, dos fatores de risco e do impacto na saúde humana, promovendo debates e reflexões fundamentais para o desenvolvimento desta temática.

Em 1992, a Organização M undial da SaúdeO M S inicia um trabalho conjunto com o Centro de M edicina Coletiva de Buffalo, estabelecendo uma comissão com o objetivo de delinear uma política de Habitação Saudável, baseada na estratégia de ambiente saudável como ferramenta de Promoção da Saúde.

Em continuidade, em 1994, a Organização Pan-americana da Saúde identificou nas regiões das Américas atores interessados em promover ambientes saudáveis nos espaços funcionais da habitação. Em 1995, é criada a Red Interamericana de laVivienda Saludable, uma iniciativa panamericana integrada inicialmente por sete países e que, em 2005, já contava com a participação de dezesseis países 4 .

O objetivo principal da Red Interamericana de la Vivienda Saludable vem a ser o fortalecimento das capacidades nacionais para enfrentamento das questões locais e de reforço ao movimento em torno das habitações saudáveis. Para isto, promove e incentiva a produção de documentos técnicos; a participação, investigação e ação local com as comunidades; a divulgação técnico-científica; a educação continuada agregando a educação para saúde; o intercâmbio sistemático de experiências, com lições aprendidas e melhores práticas ${ }^{4}$.

Esta rede representava os interesses das redes nacionais formalmente constituídas, e estabelecia o apoio co-gestor e de facilitação da O rganização Pan-americana da Saúde/Organização M undial da Saúde (OPS/OMS), por intermédio de sua Unidade de Desenvolvimento Local e Urbano. 0 processo de desenvolvimento das atividades da Red Interamericana seria acompanhado por associados que se identificariam com os objetivos da Iniciativa Regional de Habitação Saudável e manifestariam o interesse em apoiar seu plano de trabalho.

No ano 2000, a Organização Pan-americana da Saúde iniciou um processo de divulgação e 
identificação de entidades nacionais com capacidade de desenvolver uma iniciativa de habitação saudável para o Brasil.

Ciente da importância da iniciativa, a Fundação O swaldo Cruz (FIO CRUZ), conjuntamente com a Fundação Nacional de Saúde (FU NASA) e com a Organização Pan-americana da Saúde (OPS), promoveu a Oficina M oradia e Saúde no I Congresso Internacional deEngenharia deSaúde Pública, em Recifé. Como produto da oficina, foi firmada a Carta de Intenções, marco de constituição da RedeBrasileira deH abitação Saudável (RBHS).

É então elaborado o Plano Bienal de TrabaIho, fundamentado no documento base Déficit Habitacional no Brasil ${ }^{6}$, definida a estrutura da Redeenomeado o Grupo Coordenador. Em maio do mesmo ano, a RBHS se afiliou à Red Interamericana, durante sua 5a Reunião, realizada na cidade de Havana, Cuba.

Outras iniciativas de Habitação Saudável ocorrem no campo da Habitação e do Urbanismo, preconizando, também, a elaboração de projetos que discutam o conceito ampliado de habitação, incluindo as dimensões sanitária, sociocultural epsíquica com adequação, integração efuncionalidade dos espaços físicos intra e peridomiciliares; utilização de tecnologia alternativa; pre venção de acidentes e desastres; criação de áreas de convívio para realização de atividades culturais, esporte e de lazer e observância do contexto físico-geográfico, socioambiental, cultural, climático. Estas iniciativas, em sua grande maioria, vinham acompanhadas de trabalho de educação ambiental. Podem ser citadas entre tantas iniciativas como: Arquitetura Ecológica7; D esenho U rban 08,9; Desenho Ambiental e Biocidades ${ }^{10,11,12,13,14,15,16 ;}$; Arquitetura Bioclimática ${ }^{17}$; Arquitetura da Terra $18,19,20,21$.

Assim, no esforço da articulação entre o M ovimento dePromoção da Saúdee Habitação Saudável, uma reflexão se faz necessária: como produzir conhecimento teórico e prático, visando novosemelhores projetos queintegrem ações nos campos da habitação, urbanismo, meio ambiente e saúde?

A resposta para esta reflexão se encontra no entendimento dos conceitos de habitabilidade e ambiência, detalhados no item seguinte.

Habitabilidade e ambiência: estratégias para a promoção da saúde

$\mathrm{O}$ conceito $\mathrm{H}$ abitabilidadeUrbana parte do pres- suposto de que a habitação deve ser entendida em um sentido mais abrangente e sistêmico, no sentido de pertencimento, de usufruto e de direito à cidade. Isto é, inclui a oferta e 0 acesso por parte da população à rede de infra-estrutura urbana e de acesso aos equipamentos públicos. Diz respeito à questão do pertencimento ao território e da inclusão dentro de um amplo contexto urbano, dando visibilidade ao pleno exercício defruir, usufruir e construir um espaço com qualidade de saudável/habitável22.

Nesse sentido, surgem movimentos populares como o da Reforma Urbana, cuja luta é pelo acesso dos cidadãos às cidades, visando reduzir a desigualdade social e garantir a cidadania ${ }^{23}$.

0 desafio é construir uma cidade que seja solidária, democrática, justa einclusiva. É uma nova concepção da cidade, com novas propostas deenfrentamento das questões da contemporaneidade urbana, contribuindo para que novas vozes sejam ouvidas. Entre as questões de interesse, estão à violência urbana e o desenvolvimento local; a elaboração de uma política urbana estruturada que vá além das políticas habitacionais; a criação de novas bases de economia solidária; 0 habitat social; e a implementação de fóruns de debate e discussão, capacitan do novas lideranças e permitindo novas articulações entre instituições do asfal to e das favelas.

Um outro conceito, o de Habitabilidade da Unidade Habitacional, é bem debatido na atualidade. Segundo Bonduki22, este conceito diz respeito ao conjunto de aspectos que interfeririam na qualidade de vida e na comodidade dos moradores, bem como na satisfação de suas necessidades físicas, psicológicas e socioculturais. Por meio desse conceito, poder-se-iam visualizar questões como a dos confortos ambientais: luminoso, térmico, acústico e táctil; segurança do usuário e salubridade domiciliar e do seu entorno, que seriam as mesmas questões envolvidas na fruição, usufruição e construção do espaço arquitetural.

$\mathrm{O}$ conceito de $\mathrm{H}$ abitabilidade da Unidade Habitacional está associado ao conceito de ambiência, que está relacionado à necessidade de se estar confortável em termos de: adequação sociocultural (materiais locais em que foram feitos móveis, utensílios e em que foram elaborados pisos, paredes e tetos) e adequação ambiental (temperatura, ventilação, luminosidade e da quantidade e qualidade do ruído inserido dentro do espaço arquitetural). Poderia secitar, como exemplo, projetos de Promoção da Saúde que enfocassem a recuperação da ambiência urbana, 
entre eles, o reflorestamento emergencial; a reorganização do sistema de transporte coletivo e mais projetos de ciclovias e a utilização de fontes de energia alternativa, como a solar e eólica.

Os conceitos de habitabilidade e ambiência ganham visibilidade na Promoção da Saúdeatravés do conceito da semiologia do espaço construído, o qual pode ser entendido por códigos e signos que revelam para o pesquisador-observador a identidade do espaço, sua história, cultura e costumes, trazendo, desta forma, resultados de mai or qualidadetécnica, funcional, sócio-econômica, cultural e estética ao projeto.

É preciso lembrar que se considera aqui a Promoção da Saúde como vida com qualidade e, portanto, a partir de uma abordagem que ultrapassa o modelo de história natural da doença. A Promoção da Saúde deve ser entendida a partir do modelo dos determinantes sociais da saúde e no processo de construção de políticas e espaços saudáveis, recuperando a noção de saúde-doença como processo histórico e socialmente marcado. O u seja, trabalha-se com um conceito ampliado e "positivo" de saúde, e traz-se uma crítica ao modelo biomédico hegemônico, incentivando novas práticas e uma reorientação dos serviços de saúde.

Esta é uma discussão importante, pois articula tanto o modelo atual da promoção da saúde, como do conceito "positivo" de saúde (e de afirmação da qualidade de vida), por meio dos conceitos de habitabilidade e ambiência, como 0 enfoque de risco e de prevenção através da priorização da análise do espaço construído.

A prevenção como instrumento de controle do risco de propagação de eventos pode ser focada como uma norma técnica de edificações, que direciona os projetos, para eliminar ou controlar o risco de ocorrência de eventos fatais, tais como desabamentos, incêndios eescapamento de gases nocivos ao meio ambiente e aos seus habitantes.

0 conceito de risco permanece como um caminho de aproximação e de debate, estruturando os estudos ambientais, urbanos e habitacionais e de diversos programas e projetos sociais.

$\mathrm{Na}$ temática socioambiental, o conceito de risco como resultante da atividade humana (poluição, aquecimento global, biodiversidade, entre outros) traz em seu bojo o potencial de chamar a atenção do poder público para a necessidade de percepção da complexidade dos riscos ambientais eda tomada de decisão, seja por meio da elaboração de políticas e/ou estratégias alternativas de intervenção para a gestão ecoeficiente da saúde ambiental que promovam o desenvolvimento humano sustentável.

Promove, portanto, maiores reflexões sobre local ização, construção, gerenciamento, uso e manutenção da habitação e de seu entorno, para 0 enfrentamento dos fatores de risco sobre o habitat humano ${ }^{1}$.

Segundo o Banco Mundial24, o desenvolvimento humano deve ser entendido como o processo de incorporação sistemática de conhecimentos, técnicas e recursos na construção do crescimento qualitativo e quantitativo das sociedades organizadas. Para alcançar 0 desenvolvimento, seria necessário ampliar as oportunidades dos indivíduos, dando acesso ao trabal ho eà renda, à educação, à saúde, à al imentação e a um ambiente físico limpo e seguro, que englobaria a habitação e seu entorno.

0 desenvolvimento adequado corresponde a um processo eqüitativo, participativo esustentável ${ }^{25}$. Do mesmo modo, o processo de desenvolvimento implica que o crescimento econômico amplie as bases materiais para a satisfação das necessidades humanas e que o grau de distribuição dos recursos seja estendido ao maior número de pessoas possível. Dessa forma, o conceito de desenvolvimento local é entendido como o processo social que reúne crescimento econômico, redistribuição emelhoria da qualidade de vida da comunidade a que se refere ${ }^{26}$.

0 conceito de local nos remete à noção de micro espaço, que pode ser considerado como a habitação, a quadra, o bairro, a cidade ou o município ou região. Poderia, também, ser considerado território do ponto de vista geopolítico, que definiria um território-solo ou um território como um espaço de construção, processo e produto de uma dinâmica social, política, econômica, sociocultural e sanitária.

Os conceitos de local e integral se completariam com a questão da sustentabilidade. Desenvolvimento local integrado e sustentável é um novo modo de promover o desenvolvimento que possibilita o surgimento de comunidades mais sustentáveis, capazes de suprir suas necessidades imediatas, descobrir ou despertar suas vocações locais e desenvolver suas potencial idades específicas e fomentar os intercâmbios externos, aproveitando-se de suas vantagens locais ${ }^{26}$.

O conceito de desenvolvimento sustentável traria a promessa de conciliar eqüidade social, crescimento econômico e preservação do meio ambiente por meio da associação da idéia de progresso, bem-estar físico e social e melhoria de qualidade de vida. Desenvolvimento sem progres- 
so econômico e bem-estar físico e social não seria desenvolvimento e sim crescimento quantitativo.

Dessa forma, o desenvolvimento local integrado esustentável como política pública, no caso do Brasil, passaria a ser uma estratégia comple mentar de desenvolvimento, gerando crescimento econômico e reduzindo as desigualdades sociais e regionais, com práticas políticas e sociais num sentido de ampliação e democratização do espaço público e alargamento da cidadania. E o de senvolvimento local integrado e sustentável seria o instrumento de Promoção da Saúde dentro do contexto da habitabilidade urbana e habitacional e da ambiência, trazendo a construtibilidade de ambientes promotores de saúde das populações. Entendendo a construtibilidade como o conceito referente à qualidade técnico-construtiva, ambiental e econômico-financeiro que incorpora as práticas socioculturais locais ou regionais; as tipologias construtivas (em relação à fundação, estrutura, vedações, cobertura, instalações hidráulicas, sanitárias e elétricas) e a racionalização do produto (referente a modulação, padronização, normatização, flexibilidade e durabilidade dos materiais e sistemas construtivos empregados) ${ }^{22}$.

\section{Considerações finais}

N este artigo, foi visto que a Habitação Saudável e Ambientes Favoráveis à Saúde são campos potenciais e estratégi cos da Promoção da Saúde, por meio dos seus conhecimentos e práticas que inter-relacionam a qualidadedo ambiente construído e o seu entorno, incorporando conceitos como da habitabilidade urbana e da unidade habitacional, a ambiência, a semiologia do espaço construído e a construtibilidade.

O campo da Habitação Saudável, como foi mencionado, seoriginou como uma iniciativa em 1982, apoiado pela OPS / OMS, no âmbito da América Latina, que investiu na promulgação, divulgação e difusão do conceito Saúde na Habitação ou Habitação Saudável por meio do fomento de conhecimentos, incentivo às investigações e intervenções aplicados à construção de ambientes favoráveis à saúde.

Como exposto no item 2, a iniciativa de $\mathrm{Ha}$ bitação Saudável, no seu desenvolvimento, vem procurando implementar, pelo viés político, a construção de políticas públicas saudáveis, por meio de ações que incentivem um processo intersetorial, a partir de um olhar aprofundado sobre a saúde e seus determinantes sociais. Pelo viés acadêmico, desenvolvelinhas depesquisa que incentivem: (a) a reflexão sobre o modelo dos determinantes sociais da saúde; (b) processos de construção de políticas e espaços saudáveis; (c) a recuperação da noção de saúde-doença como processo histórico e socialmente marcado; (d) novas práticas e uma reorientação dos serviços de saúde; (e) a articulação entre saberes técnicos epopulares e (f) a construção do diálogo entrea Promoção da Saúde e a H abitação Saudável pelo viés da qualidade de vida, através do desenvolvimento do concei to dehabitabilidadeurbana e da unidade habitacional, ambiência e fatores de risco físico presentes na habitação.

0 objetivo principal dessas linhas de pesquisa seria mostrar a importância da questão do espaço construído e do seu entorno como um sistema que na sua totalidade incorporaria a função e utilidade desse espaço.

Como produzir conhecimento teórico e prático visando novos e melhores projetos que integrem ações nos campos da habitação, urbanismo, meio ambiente e saúde?

0 pressuposto é o reconhecimento da interdependência entre diversos setores, quer na conservação e na proteção do meio ambiente, quer no acompanhamento do impacto queas mudanças no ambiente provocam na saúde, quer ainda nas conquistas de melhores condições de vida na habitação, no trabalho, na escola, no espaço urbano e no lazer.

O planejamento em saúde ambiental e habitacional, neste contexto, é sem dúvida uma ferramenta útil para possibilitar novas formas de pensar e de intervir no ambiente e no entorno, incluindo e valorizando as experiências vividas pela população em seu ambiente. A cidade inclusive seria pensada como lócus da (re) produção de estruturas culturais, produtivas e políticas com repercussão no campo da saúde. N esse sentido, estudos urbanos presentes no planejamento físico-territorial e no Plano Diretor seriam instrumentos de regulação pública indispensáveis para criação de ambientes favoráveisà saúde, por meio do ordenamento das cidades e da gestão ambiental integrada.

A criação de ambientes favoráveis à saúde, no campo da saúde, foi refletida e consolidada na Constituição Federal de 1988, quando houve a construção deuma nova política de saúdeno Brasil. Política que tinha olhar integral sobre 0 ambiente em todas as suas dimensões, onde estavam inseridos os indivíduos e suas famílias, incentivando, desta forma, a criação de estratégias 
como a da Saúde da Família, que estavam imbuídas de conceitos como multidisciplinariedade, territorialização, vinculação e responsabilização.

Assim, tanto a Estratégia da Saúde da Família quanto a iniciativa da H abitação Saudável vinham trabalhando com a questão do local, onde a família habita e está inserida, incorporando a sua prática, conceitos como a multidisciplinariedade, a territorialidade; a privacidade; a identidade (vinculação) e a ambiência.

A iniciativa da Habitação Saudável surge como uma proposta no sentido de unir esforços com a Estratégia da Saúde da Família, criando o Centro de Atenção Primária à Saúde da Família, Ambiente e $\mathrm{H}$ abitação, projeto piloto que analisa as possibilidades de inclusão e expansão da Estratégia da Saúde da Família, ondealém das ações de cuidado à família sejam inseridas a atenção primária ambiental e a melhoria sanitária domiciliar, ambas fundamentadas no conceito de $\mathrm{Ha}$ bitação Saudável como caminho para a Promoção da Saúde. Dessa forma, expande o número de agentes comunitários em saúde e técnicos e os capacita na temática da Habitação Saudável como caminho para a Promoção da Saúde, para a percepção dos riscos ambientais e habitacionais existentes em áreas precárias urbanas².

Mostra-se, portanto, que Habitação Saudável e a Estratégia da Saúde da Família, como estratégias importantes dentro da Promoção da Saúde, necessitam para uma maior resolutividade, um olhar integral sobre 0 ambiente em suas dimensões físicas, socioculturais e biopsicossociais, o que certamente induz ao desenvolvimento de ações intersetoriais, aliando mobilização social, eqüidade, justiça social e defesa pública da saúde. A implementação de espaços sau dáveis depende da elaboração de políticas públicas saudáveis. Políticas elaboradas a partir do estudo e da reflexão sobre a leitura do espaço físico, seja macro urbano ou micro habitacional, leitura essa que promova a maior identidade com a realidade local e dê maior visibilidade às aspirações e desejos individuais e coletivos, adicionando e incorporando o conceito de habitação saudável.

A Promoção da Saúde - a saúde pública e a saúde ambiental em uma perspectiva integral - é um produto de políticas públicas que incorporam o desenvolvimento tecnológico, científico, político, social e econômico, tanto em termos local como de responsabilidade global ${ }^{27} \mathrm{com}$ diferentes cenários e de ações de sustentabilidade. Os diferentes contextos habitacionais e ambientais que acompanham o indivíduo em seu desenvolvimento - creches, escolas, universidades, lo- cais de trabalho, hospitais, entre outros, são vistos como componentes essenciais dos programas de Promoção da Saúde. A habitação traduz-se como um dos primeiros e mais vulneráveis espaços de Promoção da Saúde. Tanto o desenho como a própria Política Habitacional devem favorecer o cumprimento das funções biológicas e sociais, já que do ponto de vista do paradigma do ambiente, a habitação se constitui em um espaço de construção da saúde e consolidação do seu desenvolvimento.

É necessário o estabelecimento de alianças e propostas estratégicas para concentrar esforços e recursos a partir das potencialidades das instituições acadêmicas e públicas envolvidas com as questões sociais da saúde e da habitação.

Programas e projetos de intervenções habitacionais implantados devem traduzir uma orientação, um planejamento e uma decisão política, pressupondo a compreensão do contexto sociocultural, histórico egeográfico-ambiental que molda e condiciona o desenvolvimento humano e a qualidade de vida.

Enfim, o que se propõe é incentivar a Promoção da Saúde, enquanto estratégia que ultrapassa o setor da saúde, contemplando as questões ambientais e habitacionais, dentro dos determinantes sociais da saúde e da qualidade de vida. Uma estratégia que busca junto à diversidade de atores e sujeitos, um diálogo democrático, participativo e intersetorial, em prol de múltiplas ações de melhoria da qualidade de vida e de mudança social.

\section{Colaboradores}

SC Cohen trabalhou na concepção, delineamento e redação inicial dentro de um enfoque conceitual do campo da Habitação Saudável. R Bodstein, WB M arcondes trabalharam na concepção teórica ena discussão conceitual do campo da Promoção da Saúde. SC Cohen e DC Kligerman trabalharam na concepção teórica e na discussão conceitual do campo da Habitação Saudável e na articulação entre Promoção da Saúde e Habitação Saudável. SC Cohen, R Bodstein, DC Kligerman e WB M arcondes trabalharam na revisão crítica e aprovação da versão a ser publicada. 


\section{Referências}

1. Cohen SC. H abitação saudável como um caminho para a promoção da saúde [tese de doutorado]. Rio de Janeiro: Escola Nacional de Saúde Pública, Fundação Oswaldo Cruz; 2004

2. Cohen SC et al. Habitações saudáveis no Sus, uma estratégia de ação para o PSF: uma incorporação do conceito de habitação saudável na política pública de saúde e ambiente. Rev C S Col 2004; 9(3):807-813;

3. Buss PM. Promoção da saúde no Brasil [palestra]. Seminário Brasileiro de Efetividade da Promoção da Saúde. 10 de maio de 2005. Rio de Janeiro, Brasil.

4. Organização Pan-americana de Saúde. Portal de Moradia Saudável. [acessado $2005 \mathrm{M}$ ai 14]. Disponível em: http://www.cepis.ops-oms.org/indexpor.html

5. Rede Brasileira de Habitação Saudável. Documentos. [acessado 2005 Mai 10]. Disponível em: http:// www.ensp.fiocruz.br/rbhs/index.html

6. Fundação João Pinheiro. Inadequação habitacional.In: Déficit habitacional no Brasil 2000. Belo Horizonte: Fundação João Pinheiro; 2000.

7. Yeang K. Proyectar con la naturaleza. Bases ecológicas para el proyecto arquitectónico. Barcelona: Editorial Gustavo Gili, S.A.; 1999.

8. Del Rio V. Introdução ao desenho urbano no processo de planejamento. São Paulo: Pini; 1990.

9. Romero MAB. Princípios bioclimáticos para o desenho urbano. São Paulo: P.W.; 1988.

10. Romero MAB. A sustentabilidade do ambiente urbano da capital. In: Paviani A, Gouvêa LA, organizadores. Brasília: controvérsias ambientais. Brasília: Editora UnB; 2003.

11. Pena-Vega A. 0 despertar ecológico, Edgar M orin e a ecologia complexa. Idéias sustentáveis. Rio de Janeiro: Garamond; 2003.

12. Register R. Ecocities, building cities in balance with nature. California: Berkeley Hills Book; 2002.

13. Ribas $O$. A sustentabilidade das cidades: os instrumentos de gestão urbana e a construção da qualidade ambiental [tese de doutorado]. Braślia: CDS/ UnB; 2003.

14. Rogers R, Gumuchdjiam P. Cidades para um pequeno planeta. Barcelona: Editorial Gustavo Gilli; 1997.

15. Ruano M. Ecourbanism: sustainablehuman settlements: 60 cases studies. Barcelona: Editorial Gilli; 2000.
16. Rueda S. M odelos de ciudad: indicadores básicos. Las escalas de la sostenibilidade. Barcelona: Quaderns D'Arquitetura eU rbanismo. Collegio D' Arquitetos de Catalunya; 2000.

17. Rivero R. Arquitetura e clima: acondicionamento térmico natural. Porto Alegre: D.C.Luzzatto Editores; 1986.

18. Justi Pisani M A. Arquitetura com terra. In: Bruna GC, organizador. Promoção do desenvolvimento sustentável: comunidades do semi-árido. Relatório técnico. Universidade Presbiteriana M ackenzie; 2004.

19. M inke G. M anual de construccion en tierra: la tierra como material de construcción y sus aplicaciones en la arquitectura actual. Uruguay: Nordan-Comunidad; 2001.

20. Schmidt CB. Construções de taipa: alguns aspectos de seu emprego e da sua técnica. São Paulo: Secretaria da Agricultura; 1946.

21. Vasconcellos SC. Arquitetura no Brasil: sistemas construtivos. 4a . ed. Belo Horizonte: Escola de Arquitetura da Universidade Federal de M inas Gerais; 1961.

22. Bonduki N. Tendências e perspectivas na avaliação de políticas e programas sociais - uma metodologia para avaliar programas de habitação. São Paulo: IEE/PUCSP; 2002.

23. Silva AA. Reforma urbana e o direito à cidade. Porto Alegre: Revista Polis; 1991. Disponível em: http:// www.polis.org.br

24. Banco M undial. Informe sobre o desenvolvimento mundial. Washington: Banco Mundial; 1991.

25. Cepal. El desarollho sustentable: transformación productiva, equidad y medio ambiente. Santiago de Chile: CEPAL, Doc. LC / G 1698; 1991.

26. Cadernos da O ficina Social. D esenvolvimento local. Rio de Janeiro: Oficina Social; 2000.

27. Kickbusch I. The end of public health as we know it [conferência]. Seminário "O futuro da saúde pública: uma nova visão para as Américas". setembro de 2004; ENSP, Rio de Janeiro.

Artigo apresentado em 24/10/2005

Aprovado em 14/02/2006

Versão final apresentada em 17/03/2006 